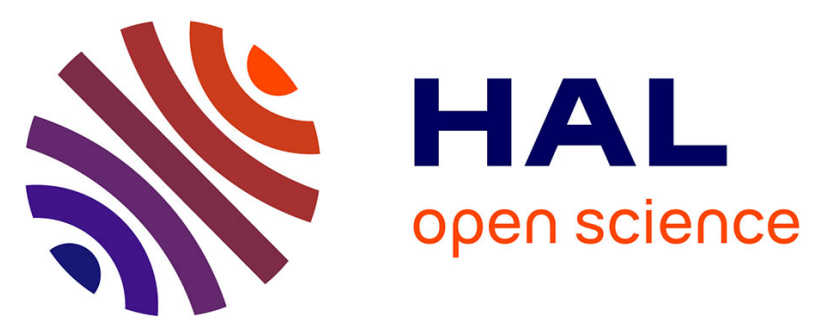

\title{
Thermomechanical Behavior of an Fe-Based Shape Memory Alloy: Transformation Conditions and Hystereses
}

\author{
K. Tanaka, F. Nishimura, H. Tobushi, E. Oberaigner, F. Fischer
}

\section{To cite this version:}

K. Tanaka, F. Nishimura, H. Tobushi, E. Oberaigner, F. Fischer. Thermomechanical Behavior of an Fe-Based Shape Memory Alloy: Transformation Conditions and Hystereses. Journal de Physique IV Proceedings, 1995, 05 (C8), pp.C8-463-C8-468. 10.1051/jp4:1995870 . jpa-00254119

HAL Id: jpa-00254119

https://hal.science/jpa-00254119

Submitted on 1 Jan 1995

HAL is a multi-disciplinary open access archive for the deposit and dissemination of scientific research documents, whether they are published or not. The documents may come from teaching and research institutions in France or abroad, or from public or private research centers.
L'archive ouverte pluridisciplinaire HAL, est destinée au dépôt et à la diffusion de documents scientifiques de niveau recherche, publiés ou non, émanant des établissements d'enseignement et de recherche français ou étrangers, des laboratoires publics ou privés. 


\title{
Thermomechanical Behavior of an Fe-Based Shape Memory Alloy: Transformation Conditions and Hystereses
}

\author{
K. Tanaka, F. Nishimura, H. Tobushi*, E.R. Oberaigner** and F.D. Fischer** \\ Department of Aerospace Engineering, Tokyo Metropolitan Institute of Technology, Asahigaoka 6-6, \\ J-193 Hino, Tokyo, Japan \\ * Department of Mechanical Engineering, Aichi Institute of Technology, Yagusa, J-470-03 Toyota, Japan \\ ** Institute of Mechanics, University for Mining and Metallurgy, A-8700 Leoben, Austria
}

\begin{abstract}
Transformation/thermomechanical behavior in an Fe-9\% Cr-5\% Ni-14\% Mn-6\%Si polycrystalline shape memory alloy during thermomechanical loading is investigated. The transformation lines in the stress-temperature plane are strongly influenced by the parameters characterizing the thermomechanical loading. The transformation start condition, the martensite start stress and the austenite start temperature, is carefully measured to compare the results with the other experimental and theoretical observations. The stress-strain-temperature hysteresis loops, full and sub, are determined during cyclic loading.
\end{abstract}

\section{INTRODUCTION}

Fe-based shape memory alloys are attracting attention as the third shape memory alloy system, following TiNi alloys and $\mathrm{Cu}$-based alloys, which can be used in the practical applications [1-4]. The high strength and low cost of the Fe-based alloys are promoting them to be used for the large size shape memory devices, such as the fasteners of pipes. The flexibility of the alloy designing is also the point to be noted in these alloys. Such alloy performances as the workability, transformation temperatures, corrosion resistance and oxidation resistance are found to be accomplished by adjusting the chemical composition and selecting the appropriate processing procedures $[5,6]$.

In order to design effectively the shape memory devices exhibiting the required high performances one needs the continuum mechanical framework which describes macroscopically the transformation and thermomechanical behaviors of the alloys under thermomechanical loading. The task of constructing the theory has to be strongly supported, before anything, by the accumulation of the experimental data in the shape memory alloys under many thermomechanical conditions.

The present authors have been investigating the behavior in an $\mathrm{Fe}-9 \% \mathrm{Cr}-5 \% \mathrm{Ni}-14 \% \mathrm{Mn}-6 \% \mathrm{Si}$ polycrystalline shape memory alloy during thermomechanical loading [7-11]. Emphasis was specially placed on such topics as the transformation lines, the hysteresis loops during cyclic loading and the subloops due to incomplete transformations. The alloy is revealed to have no temperature range of the pseudoelasticity. The thermomechanical loading, a mechanical loading followed by a thermal loading, is therefore necessary to realize the shape recovery. The transformation start stress and temperature depend strongly on the extent of prior transformations, which behavior is quite different from that observed in TiNi alloys and that predicted by the thermodynamic theories [12-14].

\section{ALLOY SAMPLE, EXPERIMENTAL APPARATUS AND EXPERIMENTAL PROCEDURE}

The alloy material was prepared by vacuum induction melting. After hot rolling, the plates were homogenized at $1323 \mathrm{~K}$ for $3.6 \mathrm{ks}$. Test specimen shown in Fig.1, $6 \mathrm{~mm}$ in diameter and $20 \mathrm{~mm}$ in gauge length, was machined from the plate [10]. Tests were carried out with a servo-hydraulic thermal fatigue testing machine equipped with a high frequency induction heater, with which both the mechanical and thermal cyclic loads were applicable independently in any form of time history. The tensile displacement was measured with a differential transformer, whereas the temperature of the specimen was detected with a platinum platinum-rhodium thermocouple spot-welded at the center in the gauge length. 
Before each experiment in this study, in order to obtain a stable data, each specimen was subjected to 4 of the following thermomechanical training cycles [7]: The specimen was first mechanically loaded to $4 \%$ strain at RT, and was unloaded. Heating to $873 \mathrm{~K}$ under free-stress and holding for $600 \mathrm{~s}$ were then followed by cooling back to RT.

A thermomechanical loading applied to the specimen is, as illustrated in Fig.2, composed of an isothermal mechanical branch, a loading/unloading between the lower limit stress $\sigma_{h}$ and the upper limit stress $\sigma_{\max }$ at a hold temperature $T_{h}$, and a subsequent isostatic thermal branch, a heating/cooling between the lower limit temperature $T_{h}$ and the upper limit temperature $T_{\max }$ under a hold stress $\sigma_{h}$.

The martensite start stress $\sigma_{\mathrm{Ms}}$ was measured from the stress-strain output during the mechanical branch of cycling as a $0.05 \%$ proof stress, whereas the austenite start temperature $\mathrm{T}_{\mathrm{As}}$ and the austenite finish temperature $\mathrm{T}_{\mathrm{Af}}$ were detected as the points with zero-inclination on the strain-temperature curve during thermal branch of loading.

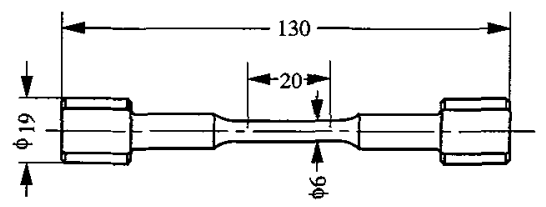

Figure 1: Specimen.

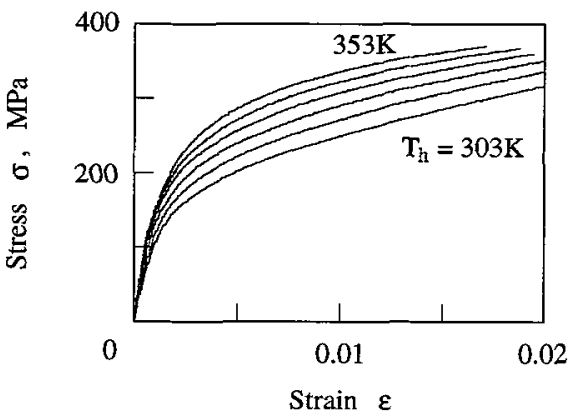

Figure 3: Stress-strain curves.

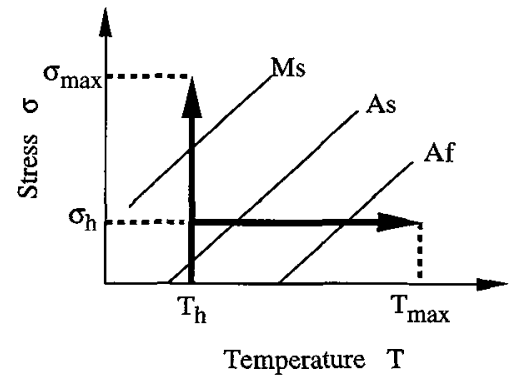

Figure 2: Thermomechanical loading.

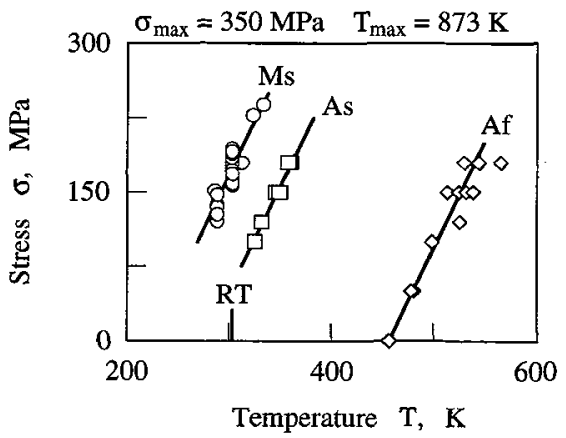

Figure 4: Transformation lines.

\section{BASIC ALLOY PERFORMANCE; TRANSFORMATION LINES}

Figure 3 shows the stress-strain curves at the temperatures every $10 \mathrm{~K}$ from $303 \mathrm{~K}$ to $353 \mathrm{~K}$. The nonlineality of the curves stems from the stress-induced martensitic transformation. For the loading paths of the type shown in Fig.2 one can draw the martensitic/reverse transformation start/finish lines in this alloy sketched in the stress-temperature plane (cf. Fig.4). It should be noted that the results of As and Af lines in Fig. 4 are obtained after preloading of $\sigma_{\max }=350 \mathrm{MPa}$ at $\mathrm{T}_{\mathrm{h}}=\mathrm{RT}$.

Typical characteristics of the present Fe-based alloy are as follows: The martensitic transformation finish line cannot be detected. The As and Af points are about $278 \mathrm{~K}$ and $457 \mathrm{~K}$, respectively. The transformation lines are almost linear and parallel with the slop of about $2.17 \mathrm{MPa} / \mathrm{K}$. The martensitic transformation zone and the reverse transformation zone are apart each other in the plane, and the reverse transformation zone is very wide, $\mathrm{T}_{\mathrm{Af}}-\mathrm{T}_{\mathrm{As}} \approx 180 \mathrm{~K}$. In the case of smaller value of $\sigma_{\max }$, in other words, for the smaller extent of martensitic transformation, the As-line shifts to the higher temperature side with almost no change in the slope whereas the Af-line to the lower temperature side [9]. 


\section{TRANSFORMATION START STRESS/TEMPERATURE AFTER INCOMPLETE TRANSFORMATIONS}

The martensite start stress $\sigma_{\mathrm{Ms}}$ and the austenite start temperature $\mathrm{T}_{\mathrm{As}}$ after the incomplete transformations were revealed to depend strongly on the extent of the prior martensitic and reverse transformations as summarized in Figs.5 and 6 . Figure 5 is obtained by measuring the martensite start stress after thermomechanical loading shown in Fig. 2 with $\sigma_{\mathrm{h}}=0 \mathrm{MPa}, \mathrm{T}_{\mathrm{h}}=\mathrm{RT}$ and the different values of $\sigma_{\max }$ and $\mathrm{T}_{\max }$. The martensitic transformation is always incomplete, and so is the reverse transformation when $\mathrm{T}_{\max }$ $<$ Af (The same is true in the tests leading to Fig.6). The fine line in the figure shows the stress-"plastic" strain curve during monotonic loading whereas the dotted curve connecting the yield stresses (the solid points) measured during successive loading-unloading-reloading. The difference between these two curves stems from the definition of the proof stress. The austenite start temperature given in Fig. 6 is obtained for the thermomechanical load with $\sigma_{\max }=300 \mathrm{MPa}, \sigma_{\mathrm{h}}=0 \mathrm{MPa}, \mathrm{T}_{\mathrm{h}}=\mathrm{RT}$ and the different values of $\mathrm{T}_{\max }$. The fine line denotes the monotonic dilatation curve during heating whereas the solid points stand for the austenite start temperature in a successive heating-cooling-reheating process. The two parameters, $\left(\sigma_{\max }\right.$, $\varepsilon_{R}$ ) or $\left(T_{\max }, \varepsilon_{R}\right)$, are necessary to determine the transformation start condition, where $\varepsilon_{R}$ denotes the residual strain induced after the mechanical unloading or thermal cooling.

Similar alloy performance is observed in $\mathrm{Cu}-\mathrm{Zn}-\mathrm{Al}$ and $\mathrm{Cu}-\mathrm{Al}-\mathrm{Mn}$ alloys [15], $\mathrm{Cu}-\mathrm{Zn}-\mathrm{Al}$ alloy [16], $\mathrm{Fe}-$ Mn-Si alloy [17] and Fe-Mn-Si-Cr-Ni-Co alloy [18]. Paskal and Monasevich [19], however, observed in the TiNi alloys that the martensite and austenite start temperatures are totally independent of the extent of the prior transformations in the process of thermal loading/unloading under no applied stress. Tanaka $e t$ al. [10] also confirmed the same phenomenon in a TiNi alloy in the pseudoelastic temperature range.

The thermodynamic prediction [12-14] claims different response in the shape memory alloys: The martensite start condition and the austenite start condition coincide to be a linear line, which is reduced, under the thermomechanical loading studied here, to a bi-linear line in the stress-strain-temperature plane sketched with a dotted line in Fig.7. The present experiments correspond to the fine lines in the figure. According to thermodynamics of the martensitic transformations [20] the transformation starts at a material point when the condition

$$
\Delta \mathrm{G}(\boldsymbol{\sigma}, \mathrm{T})=-\mathrm{G}_{0}
$$

is satisfied, where $\Delta \mathrm{G}$ is called the driving force and $\boldsymbol{\sigma}$ and $\mathrm{T}$ stand for the local stress and the temperature at the material point. The case $\mathrm{G}_{0}=0$ corresponds to the above-mentioned thermodynamics prediction (the bilinear line in Fig.7). The present data can be qualitatively explained by assuming that the threshold value $\mathrm{G}_{0}$ depends on the extent of the prior transformation $[21,22]$.

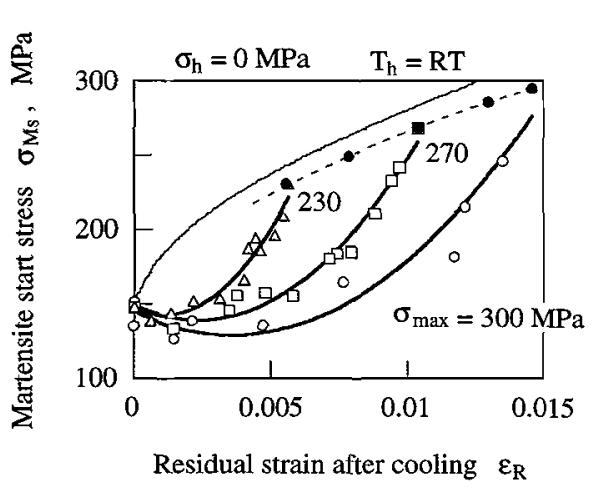

Figure 5: Martensite start stress.

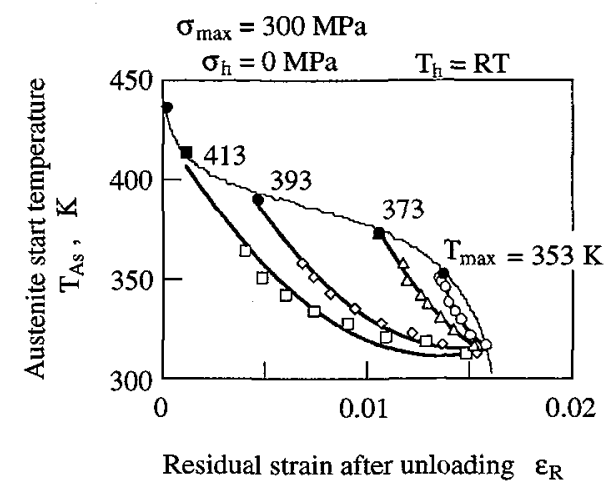

Figure 6: Austenite start temperature.

\section{EFFECT OF HOLD STRESS/TEMPERATURE ON TRANSFORMATION CONDITION}

Assuming that the same value of the transformation strain $\varepsilon_{\mathrm{T}}$ means the same extent of transformation, one can investigate the temperature-dependence of $\sigma_{\mathrm{Ms}}$ with the use of the specimens which are pre-transformed to the same $\varepsilon_{\mathrm{T}}$ at a hold temperature $\mathrm{T}_{\mathrm{h}}$. The results are plotted in Fig. 8 for $\varepsilon_{\mathrm{T}}=0.01$, in which the data labeled by $\mathrm{T}_{\mathrm{h}}=303 \mathrm{~K}$ are the same data labeled by $\sigma_{\max }=300 \mathrm{MPa}$ in Fig.5. The hold temperature dependence of the transformation start stress is clear, and the hold temperature should be added to the third parameter, following $\sigma_{\max }$ and $\varepsilon_{R}$, to estimate $\sigma_{M s}$. 
To investigate the effect of the hold stress on the austenite start temperature, a reference state of transformation in the test specimen is assumed to be characterized by a value of the recovery rate $R=\left(\varepsilon_{T}-\right.$ $\left.\varepsilon_{R}\right) / \varepsilon_{T}$; the rate of the recovery strain $\varepsilon_{T}-\varepsilon_{R}$ during reverse transformation to the transformation strain $\varepsilon_{T}$ induced during martensitic transformation. The results for the case of $R=0.72$ are summarized in Fig.9, which reveals evident dependence of the hold stress. The data are replotted in the stress-temperature plane to give a clearer view of the transformation lines (cf. Fig.10). The lines represent the austenite start line of the specimen which has experienced the reverse transformation to an extent specified by $\varepsilon_{R}$. They are linear and almost parallel, indicating that the curves in Fig.9 are displaced in parallel along the vertical axis. The lines shift to the low temperature side with the extent of martensitic transformation.

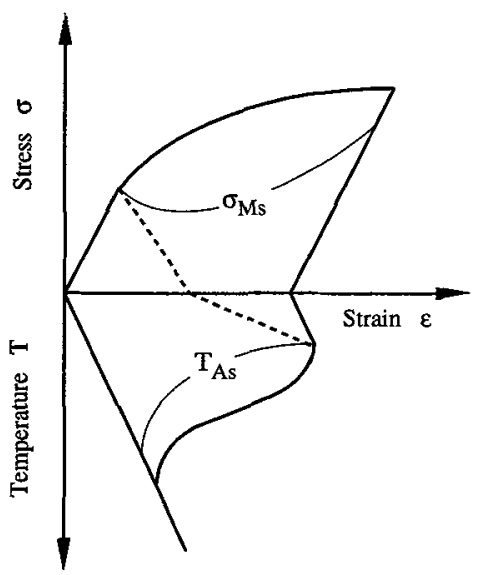

Figure 7: Transformation start lines (schematic).

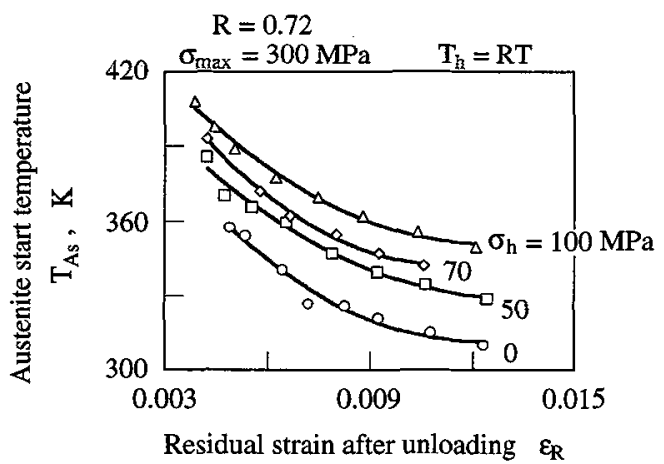

Figure 9: Effect of hold stress on austenite start temperature.

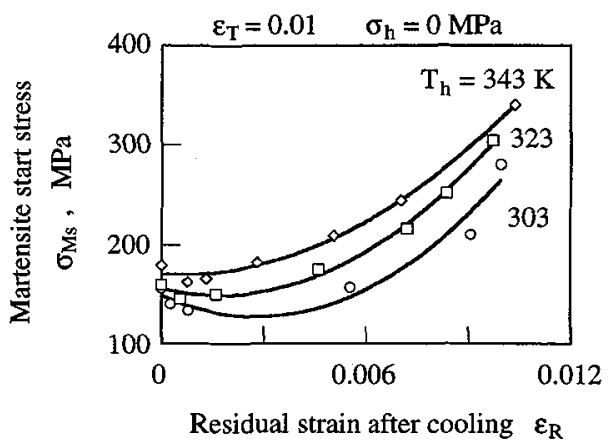

Figure 8: Effect of hold temperature on martensite start stress.

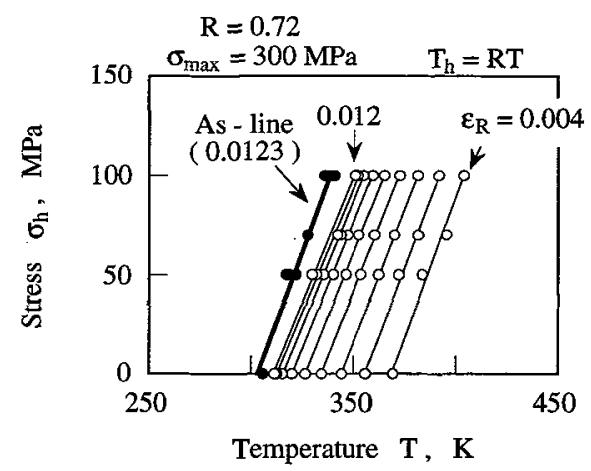

Figure 10: Transformation lines during heating.

\section{STRESS-STRAIN-TEMPERATURE HYSTERESIS UNDER THERMOMECHANICAL CYCLIC LOADING}

Under a thermomechanical cyclic loading composed of an isothermal loading/unloading and a subsequent isostatic heating/cooling sketched in Fig.2, a stress-strain-temperature hysteresis is observed. When the applied stress is controlled in the mechanical loading, a series of the hysteresis loops shown in Fig. 11 is obtained under the cyclic loading; $\sigma_{\max }=350 \mathrm{MPa}$ at $\mathrm{T}_{\mathrm{h}}=\mathrm{RT}$ and $\mathrm{T}_{\max }=873 \mathrm{~K}>\mathrm{Af}$ under $\sigma_{\mathrm{h}}=0 \mathrm{MPa}$. It should be noted that the reverse transformation always completes during heating. The hysteresis loop shifts to the higher strain side and changes its shape slightly during cycling. The drift of the loop is due to 
the accumulation of the dislocations at the defects scattered in the alloy [23]. Although the shape of the loop finally converges to a limit shape, the shift of the loop continues by a small amount cycle by cycle. This situation is different from the case of TiNi alloys, the hysteresis loop of which finally converges to a limit loop after about a hundred of cycling $[24,25]$.

Similar phenomenon is observed when the applied strain is controlled. Figure 12 shows a stress-strain-temperature hysteresis under a strain-controlled cyclic thermomechanical loading; $\varepsilon_{\max }=0.03$ at $\mathrm{T}_{\mathrm{h}}=\mathrm{RT}$ and $\mathrm{T}_{\max }=873 \mathrm{~K}>$ Af under $\sigma_{\mathrm{h}}=0 \mathrm{MPa}$. Again the reverse transformation completes in the heating process. As in the case of the stress-controlled test shown in Fig.11, the hysteresis never converges to a limit loop, at least up to 100 cycles of loading investigated. It continues drifting to both the higher strain side and the lower stress side. The shift is clearly illustrated in Fig. 13 which shows the increase in the residual strain after each cycle of thermomechanical loading. The tendency in the figure suggests that a limit shape of the hysteresis loop might be reached soon or later after a large number of cycles though it could still continue drifting.

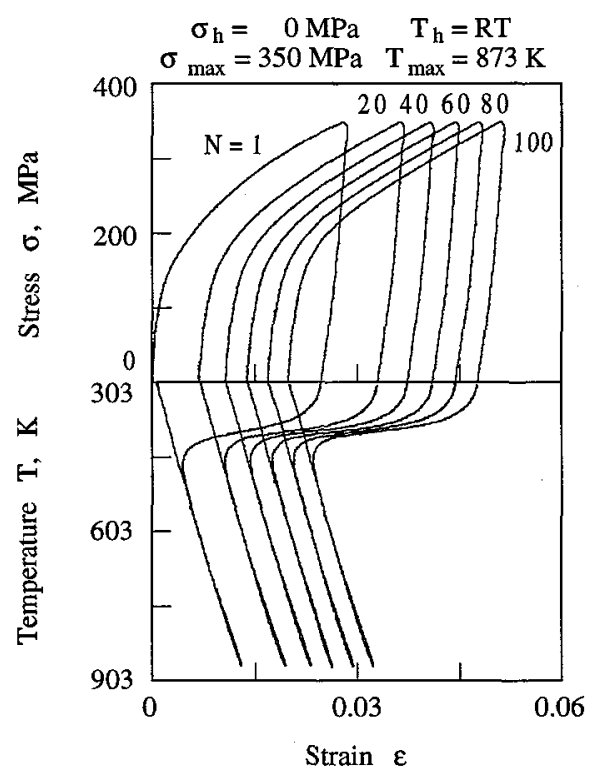

Figure 11: Thermomechanical hysteresis under stress-controlled cyclic loading.

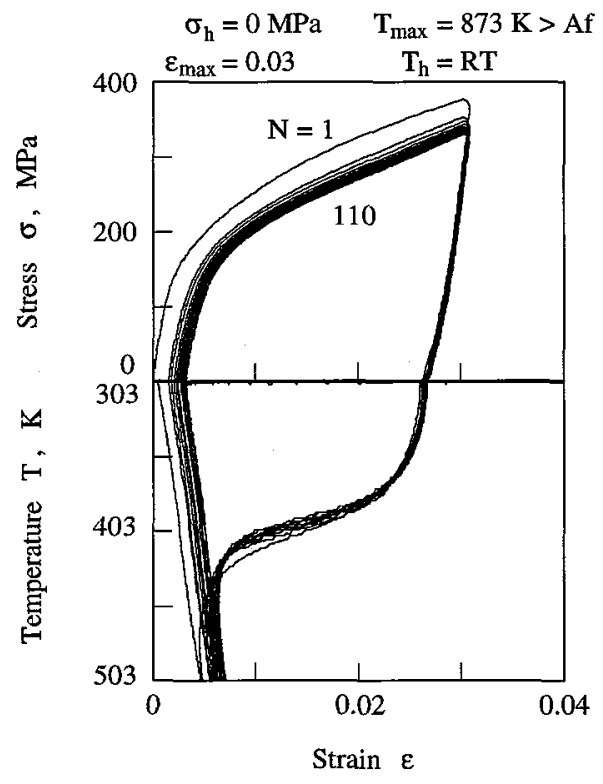

Figure 12: Thermomechanical hysteresis under strain-controlled cyclic loading.

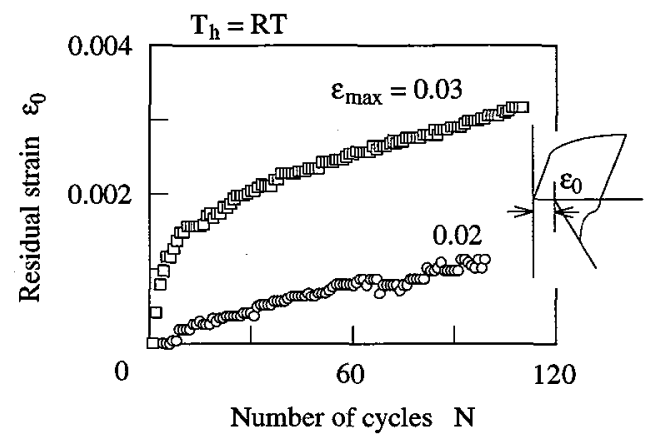

Figure 13: Change in residual strain during thermomechanical cycling. 


\section{Acknowledgments}

Part of this work was financially supported by the Special Research Fund/ Tokyo Metropolitan Government. The authors extend their gratitude to the Steel Research Center/ NKK corporation for supplying the alloy specimens.

\section{References}

[1] Maki,T. and Tamura,I., "Shape memory effect in ferrous alloys", Proc. ICOMAT 86, (1986) pp.963970.

[2] Maki,T., Materials Science Forum 56-58 (1990) 156-168.

[3] Maki,T. and Tsuzaki,K., "Transformation behaviour of $\varepsilon$-martensite in Fe-Mn-Si shape memory alloys", Proc. ICOMAT 92 (1992) pp.1151-1162.

[4] Eucken,S., ed., Progress in Shape Memory Alloys (Informationsgesellschaft Verlag, Oberursel, 1992).

[5] Sade,M., Halter,K. and Hornbogen,E., Z. Metallkd. 83 (1988) 97-104.

[6] Moriya,Y., Kimura,H., Ishizaki,S., Hashizume,S., Suzuki,S., Suzuki,H. and Sampei,T., J. Phys., IV, Colloque C4, Suppl. J. Phys. III, Vol.1 (1991) C4-433/C4-437.

[7] Tanaka,K., Hayashi,T., Aida,Y. and Tobushi,H., J. Intell. Material Syst. Struct. 4 (1993) 567-573.

[8] Tanaka,K., Hayashi,T., Nishimura,F. and Tobushi,H., J. Materials Engng Performance 3 (1994) 19.

[9] Tanaka,K., Hayashi,T., Fischer,F.D. and Buchmayr,B., Z. Metallkd. 85 (1994) 122-126.

[10] Tanaka,K., Nishimura,F. and Tobushi,H., Mech. Materials 19 (1995) 271-280.

[11] Tanaka,K., Nishimura,F. and Tobushi,H., Z. Metallkd. 86 (1995) 211-215.

[12] Müller,I., Continuum Mech. Thermodyn. 1 (1989) 125-142.

[13] Müller,I. and Xu,Huibin, Acta Metall. Mater. 39 (1991) 263-271.

[14] Raniecki,B., Lexcellent,Ch. and Tanaka,K., Arch. Mech. 44 (1992) 261-248.

[15] Amengual,A., Cesari,E. and Segui,C., "Subloop behaviour in the thermoelastic martensitic transformations", Proc. ICOMAT 92, C.M.Wayman and J.Perkins, eds. (Institute for Advanced Studies, Carmel, 1993) pp.377-382.

[16] Wei,Zhongguo and Yang,Dazhi, Scr. Metall. 22 (1988) 1245-1249.

[17] Robinson,J.S. and McCormick,P.G., Mater. Sci. Forum 56-58 (1990) 649-654.

[18] Tan,Shiming and Yang,Shiwei, Scr. Metall. Mater. 27 (1992) 229-232.

[19] Paskal,Yu.I. and Monasevich,L.A., Phys. Met. Metallogr. 53 (1981) 95-99.

[20] Kaufman,L. and Hillert,M., "Thermodynamics of Martensitic Transformations", Martensite, G.B.Olson and W.S.Owen, eds. (ASM International, 1992) Chap.4.

[21] Levitas, V.I., Mech. Research Commun. 21 (1994) 273-280.

[22] Raniecki,B. and Lexcellent,Ch., Euro. J. Mech., A/ Solids, 13 (1994) 21-50.

[23] Miyazaki,S., Imai,T., Igo,Y. and Otsuka,K., Metall. Trans. A 17A (1986) 115-120.

[24] Tobushi,H., Iwanaga,H., Tanaka,K., Hori,T. and Sawada,T., Continuum Mech. Thermodyn. 3 (1991) 79-93.

[25] Tobushi,H., Iwanaga,H., Tanaka,K., Hori,T. and Sawada,T., JSME Int. J., Ser.I 35 (1992) 271 277. 